\title{
CRISE AMBIENTAL: \\ Ponderando a Respeito de um Dilema da Modernidade ${ }^{1}$
}

\author{
AMBIENT CRISIS: \\ Pondering Regarding a Quandary of Modernity
}

Maurício Waldman ${ }^{*}$

\begin{abstract}
RESUMO: A questão ambiental transfigurou-se como um fato central na vida contemporânea. Nesse sentido, avaliar as especificidades da crise ambiental da Modernidade configura tema básico para compreender a questão ambiental, tanto nos seus aspectos mais amplos quanto nos específicos. Particularmente, a contraposição entre Tradição e Modernidade - que referenciam temáticas próprias no tocante à questão ambiental - conquistam relevo especial. Comparativamente, ainda que no passado seja possível identificar a irrupção de crises ambientais, essas pouco ou nada se relacionam com a crise ambiental da Modernidade. Isso porque a gênese e formas de manifestação das crises ambientais do mundo da Tradição e da Modernidade diferem em todos os sentidos. A crise ambiental das sociedades tradicionais foi demarcada pela naturalidade e a da modernidade, pela artificialidade. Ademais, a sociedade contemporânea enfrenta dificuldades manifestas em afiançar seu padrão de utilização dos recursos naturais. Basicamente em função do esgotamento das possibilidades de expansão continuada do sistema. Nesse sentido, a crise ambiental da modernidade demarca uma fronteira civilizatória, apontando para a necessidade de revisão das prioridades e das perspectivas que seriam matriciais para a própria continuidade do mundo moderno. É essa a ponderação que o texto que segue coloca como questão chave: o dilema de uma civilização que busca satisfação ilimitada com base em recursos finitos. 0 que impõe a revisão urgente dos seus objetivos, prerrogativas e intenções.
\end{abstract}

PALAVRAS-CHAVE: Tradição, Modernidade, Questão Ambiental, Tempo-Espaço, Repensar.

ABSTRACT: The environmental issue transfigured as a central fact of contemporary life. In this sense, to evaluate the specifics of the environmental crisis of Modernity configure basic theme in order to understand the environmental issue, both in its broader aspects and the specifics. In particular, the contrast between Tradition and Modernity - that refer to themselves in terms of thematic environmental issue - gain special importance. Comparatively, in the past is still possible to identify the emergence of environmental crises, these crises has little or nothing to do with the environmental crisis of modernity. This is because the genesis and forms of manifestation of environmental crises in the world of Tradition and Modernity differ in every way. The environmental crisis of traditional societies were demarcated by naturalness and environmental crisis of Modernity is dermacate by artificiality. Furthermore, contemporary society faces difficulties experienced in securing their pattern of use of natural resources. Mainly due to the exhaustion of continued expansion of the system. In this sense, the environmental crisis of Modernity marks a civilization frontier, pointing to the need to review priorities and perspectives that would be continued to the very matrix of the modern world. This is the weight that puts the text that follows as a key issue: the dilemma of a civilization that seeks unlimited satisfaction based on finite resources. What requires urgent review of its objectives, prerogatives and intentions.

KEYWORDS: Tradition, Modernity, Environmental Issue, Time-Space, Rethinking.

\footnotetext{
1 Paper elaborado para o IX Encontro Anual de Extensão (ENAEXT) e IV Fórum Regional de Meio Ambiente da UNOESTE, Universidade do Oeste Paulista, Presidente Prudente (SP), aos 20-10-2011.

* Pós-Doutor pelo Departamento de Geografia do Instituto de Geociências da UNICAMP. No âmbito da USP, Maurício Waldman tem graduação em Sociologia, Mestrado em Antropologia e Doutorado em Geografia. Foi Chefe da Coleta Seletiva de Lixo da Capital paulista e Coordenador do Meio Ambiente em São Bernardo do Campo. É autor de 14 livros, dentre os quais Lixo: Cenários e Desafios (Cortez Editora, 2010), publicação indicada como finalista para a $53^{a}$ edição do Premio Jabuti na categoria de melhor livro de Ciências Naturais. Atualmente, colabora com a formatação da proposta de curso de pós-graduação em Meio Ambiente da UNOESTE - Universidade do Oeste Paulista. E-mail: mw@mw.pro.br. Home-page: www.mw.pro.br.
} 
Discutir a questão ambiental na conjuntura atual suscita, por definição, reflexões sobre a Modernidade e os desequilíbrios ecológicos que marcaram sua trajetória no tempo e no espaço². Mais: adotando a noção de que a relação homem-natureza se corporifica pelo signo da contradição, tal discussão se imporia, pois pelo simples motivo de que nesse momento da história humana, essa atingiu as raias do paroxismo.

A sociedade moderna, tendo colocado sob sua égide toda a extensão do ecúmeno ${ }^{3}$, chegou a uma espécie de situação limite, passível de transfigurar-se numa espécie de ponto de não retorno. Nesse particular, não haveria como objetar: a proporção assumida pela crise ambiental é de tal monta, que permite postular que a própria sobrevivência da espécie humana está colocada em risco:

\begin{abstract}
"O exame do que significa em nossos dias o espaço habitado, deixa entrever claramente que atingimos uma situação limite, além da qual o processo destrutivo da espécie humana pode tornar-se irreversível" [...] Senhor do mundo, patrão da Natureza, o homem se utiliza do saber científico e das invenções tecnológicas sem aquele senso de medida que caracterizará as suas primeiras relações com 0 entorno natural. 0 resultado, estamos vendo, é dramático" (SANTOS, 1988:44).
\end{abstract}

Outrossim, a magnitude alcançada pelos problemas ecológicos justifica esforços direcionados na sua compreensão, assim como entender os mecanismos que no interior do modo de ser do mundo ocidental, foram responsáveis pela irrupção de uma crise inédita para com o meio ambiente.

Desse modo, um primeiro ponto a ser pautado remeteria às distinções radicais que ratificaram, no tocante à Modernidade, um contexto cujos pressupostos geográficos, históricos, culturais, sociais, políticos e econômicos foram em tudo dessemelhantes aos que vigoraram no mundo tradicional. Mais amplamente, tal assertiva reportaria a uma sociedade enquadrada por parâmetros simultaneamente técnicos e unificadores, apoiada em estilos de vida que de um modo sem precedentes, desvencilharam a Humanidade dos tipos tradicionais de ordem social.

Em função das prerrogativas que endossou, o mundo ocidental sentiu-se instigado a impor suas pretensões civilizatórias para o conjunto do Planeta, inaugurando com isso uma Gessellschaft construída a seu gosto e colocada sob seu comando. Saliente-se que a opção por essa terminologia

\footnotetext{
2 Notar que muitos textos também fazem uso das terminologias ocidente, sociedade moderna, ocidental e/ou contemporânea para nominar a Modernidade, entendida enquanto padrão civilizatório hegemônico, matriz da globalização.

3 No jargão geográfico, ecúmeno seria a superfície habitável e/ou habitada da Terra. Nesse exato sentido, o espaço habitado e ecúmeno são sinônimos a toda prova. Ecúmeno constitui, pois terminologia indissociável das disciplinas e das especialidades voltadas para o estudo do território.
} 
não tem nada fortuita. No pensamento alemão, Gessellschaft (sociedade) está em oposição a Gemeinschaft (comunidade), antinomia que na ponderação do cientista social novicentista Ferdinand Tönies, foi consignada como segue:

\begin{abstract}
"Gemeinschaft representava o passado, a aldeia, a família, o calor. Tinha motivação afetiva, era orgânica, lidava com relações locais e com interação. As normas e o controle davam-se através da união, do hábito, do costume e da religião. Seu círculo abrangia família, aldeia e cidade. Já Gesellschaft era a frieza, o egoísmo, fruto da calculista modernidade. Sua motivação era objetiva, era mecânica, observava relações supralocais e complexas. As normas e o controle davam-se através de convenção, lei e opinião pública. Seu círculo abrangia metrópole, nação, Estado e Mundo" (in RECUERO, 2001).
\end{abstract}

$\mathrm{Na}$ trajetória que respaldou a afirmação deste ideário, seria cabível sublinhar que a supremacia da Modernidade se consolida com base no predomínio do tempo sobre o espaço; da noção do que é privado sobre à do coletivo; do que seria mundial sobre o que é de âmbito local; $e$ paradigmaticamente, da submissão da esfera do natural à do artificial (WALDMAN, 2010, 2008, 2006a, 2006b, 2004 e 1997).

Como resultado, a mediação com a natureza passou a ser enquadrada por determinações laicas de mundo, perdendo, pois suas imemoriais atribuições mágicas e/ou metafísicas ${ }^{4}$. Na materialização destas injunções, a Modernidade promoveu ima ambiciosa recolocação de recursos e técnicas. Entabulada com uma radicalidade nunca observada na história, ela concertou a base de uma hegemonia cujo intuito não declarado, foi garantir o bem estar de poucos em detrimento de muitos. Seu objetivo expresso, a apropriação privada do espaço e do meio natural, teve por sucedâneo o desmantelamento das formações sociais preexistentes, evento que transcorreu paralelamente à destruição da autarquia e a implantação de uma economia mundial.

Recorde-se que a ferocidade dessa investida não se restringiu à submissão dos povos e culturas postados no caminho da Gessellschaft. No que toca à relação com a natureza, a Modernidade inaugurou uma era de malbaratamento dos recursos naturais cuja escalada prossegue - em desafio manifesto aos equilíbrios da biosfera - até os dias de hoje (WALDMAN, 2011a e 2010).

Nessa perspectiva, o mundo da Tradição contrasta solenemente com essas invectivas. Apartadas da turbulência, agitação e frenesi da Modernidade, as sociedades tradicionais eram regidas por um dinamismo mais lento, legitimado pela supremacia de desígnios sociais que

\footnotetext{
4 "Até a grande experiência colonial que se inicia algo antes de 1492 e que vai até a industrialização maciça da Europa, a relação com o meio ambiente não foi pensada como dominação ou transformação da natureza, senão como um intercâmbio com forças naturais freqüentemente sacralizadas em mitos ou cosmologias religiosas" (ALIER, 1992:49).
} 
tipificavam estilos de vida e de percepção da realidade desprovidos de relação com os que triunfaram no ocidente. Tais sociedades, consideradas frias ao gosto da definição celebrizada pelo antropólogo francês Claude LÉVI-STRAUSS (1970), contextualizariam, pois, dinâmicas que mesmo distantes de um equilíbrio absoluto, se aqueciam unicamente em lapsos mais prolongados de tempo. Nessa linha de argumentação, o mundo da Tradição seria, portanto, intrinsecamente distinto das sociedades quentes, filiadas à Modernidade. Afirmação que dificilmente encontraria contestação, o homem imerso na esfera da Tradição era regido por uma psicologia social para a qual a exigência de conformidade prevalecia sobre os ímpetos de mudança (BALANDIER, 1976:235).

Implicitamente, tal averbação subentende o mundo inaugurado pela Modernidade enquanto "divisor de águas" dos processos sociais historicamente encetados pelos humanos. Nessa acepção, o Moderno termina por se posicionar como um marco que endereça à Tradição tudo o que está em desajuste com seus predicados, determinações e interesses. No que tange ao cerne dessa discussão, a oposição entre Modernidade e Tradição transparece claramente quando direcionamos o eixo da análise para a relação homem-natureza. Reportando a entendimentos diferenciados para o regramento do tempo social e a territorialização do espaço, a sociedade moderna e as que integram o mundo tradicional, esposam dinâmicas que advogam ritmos mais acelerados de transformação da natureza no primeiro caso, e mais brandos, para o segundo. Tal inferência, inscrita tanto na concretude quanto no imaginário, perpassa pela totalidade do edifício social que compõe diferencialmente 0 campo da Tradição e 0 da Modernidade.

Contudo, entenda-se que estamos nos referindo, tanto para um caso quanto para outro, de modalidades voltadas, cada uma a seu modo, para a transformação da natureza. Exatamente em vista desse arrazoado, seria cabível admoestar que o mundo tradicional - a despeito da sua predisposição em assimilar os fluxos da natureza com maior flexibilidade - não poderia ser ungido pela aura de uma idade de ouro ambiental. Tal ideação se ajustaria ao equivocado raciocínio que subentende as sociedades tradicionais como fiadoras convictas da estabilidade, isentas de contradições e de conflitos, e por extensão, pouco dispostas a colocar em movimento altercações com o meio natural.

Concepções desse tipo estariam filiadas a modelos de interpretação da realidade calcados no funcionalismo, formatando uma perspectiva marcada pela compreensão naturalista e harmônica de sociedade, sendo sua pedra de toque o conceito de totalidade social e cultural integrada. Nessa 
via de entendimento - e contrariando interpretações imersas num romantismo "ecológico" - um corolário de estudos traz a luz que não obstante os impactos pontuais das tecnologias de antanho, a repetitividade de determinados procedimentos, quando gravados pela cumulatividade, redundaram em transformações marcantes dos antigos ambientes de vida.

De fato, seções inteiras de paisagens tidas como naturais, resultaram de ações antropogênicas estreadas por variegado conjunto de caçadores-coletores, agricultores itinerantes, populações extrativistas e muitas outras difusamente catalogadas como "consorciadas" à natureza. No que constituiria notação emblemática, vastas superfícies da savana africana e sul-americana, tiveram, por exemplo - a revelia de influências edáficas e/ou climáticas - a caça pelo fogo enquanto componente genético ${ }^{5}$. Ademais, as transformações promovidas pelos humanos nos espaços savaneiros usufruiriam inclusive da consagração da senioridade. Não seria demasiado frisar, a ocupação desse ambiente, especialmente na África, remontaria ao aparecimento do gênero Homo. Ou seja: há mais de um milhão de anos atrás (HARRIS, 1982:181, RIZZINI, 1979:102, COUTINHO, 1977).

Seqüencialmente, acompanhando a ocupação do Planeta pelos humanos, seria permissivel rascunhar portentoso elenco de alterações promovidas por procedimentos tidos como "ambientalmente pouco exigentes", mas que interferindo paulatinamente no meio ambiente, decorreram na eliminação de centenas de espécies. Para conferir: houve uma época em que concentrações de uros $^{6}$ eram avistadas na Gália, na Bélgica, na Panônia e na Dácia; em tempos passados, manadas de camelos atravessavam o vale do Mississipi; noutros, leões se aqueciam ao Sol da Macedônia, Numídia, Pérsia, da Lacedemônia e do Bokhara; poucos milênios atrás, crocodilos se refestelavam no delta do rio Nilo e rinocerontes, chafurdavam nos rios da Borgonha; mais recentemente ainda, lobos caçavam nos campos da Nortúmbia, do Danelaw e da Cornualha e os mares nórdicos, pululavam de leões marinhos. Pelo que é possivvel entender, uma indagação não se permite calar: Pois bem, onde foram parar estes admiráveis espécimes da fauna terrestre? (WALDMAN, 2006b:66).

\footnotetext{
${ }^{5}$ Caberia atestar que cerrado constitui terminologia biogeográfica concernente à paisagem savaneira sul-americana, particularmente a do Brasil.

${ }^{6}$ Os uros, uris ou auroques são descritos em várias fontes latinas e em narrativas celtas. Elas se referem a um tipo de bovídeo gigantesco, que vivia profusamente na Europa Ocidental ainda nos tempos da conquista romana da Gália. Júlio César deixou-nos a seguinte menção ao animal, extinto no século XVII: "Esses uri têm quase o tamanho dum elefante, mas de natureza, cor e forma são touros. Eles têm muita força e grande velocidade: não poupam nem homem nem animal uma vez que os avistem" (Commentarii de Bello Gallico). As imagens mais conhecidas dos uros estão retratadas no complexo de Lascaux, França. Especialistas em heráldica, numismática e toponímia creditam aos uros a procedência de imagens e referências espaciais difusas em muitos produtos culturais da Europa e da Ásia.
} 
Outra consideração - freqüentemente marginalizada na sua implicação ambiental - é que todas as migrações humanas deixaram atrás de si um rastro de devastação decorrente da instauração dos novos assentamentos. Na ilha de Malta, no Mediterrâneo, o elefante anão, autêntica relíquia zoológica, desapareceu logo nas primeiras vagas de ocupação humana. Na Nova Zelândia, muito antes dos europeus, os Maori extinguiram o moa, uma magnífica ave da Oceania. Durante 0 Paleolítico, nos eventos que acompanharam o povoamento da América, os homens e mulheres que cruzaram o estreito de Bering 14.000 anos atrás vindos da Ásia ${ }^{7}$, foram cúmplices do extermínio de numerosas espécies da fauna em seu trajeto rumo ao sul. Nessa nova extensão ocupada pelos humanos, grandes animais como o mamute, o cavalo, o camelo, a preguiça gigante, o tigre de dentes de sabre, leões e cães selvagens, além de muitas espécies da avifauna, foram implacavelmente dizimados e extintos para sempre (Cf WALDMAN, 2006a e 2006b, TAKS et FOLADORI, 2002, PASCHOAL, 1978:7).

Concretamente, nenhuma parte do ecúmeno permaneceu incólume à orquestração dos humanos. Foi o que ocorreu em Madagascar, a grande ilha africana ocupada por expedições de navegantes malaios em tempos não muito remotos ${ }^{8}$. Esses intrépidos povoadores, que desafiaram a imensidão do Índico, foram responsáveis pela introdução de muitas espécies de procedência asiática, da rizicultura em terraços e por demandas inéditas por recursos, se empenhando num manejo da paisagem que declinou em metamorfoses ambientais irreversíveis. Destino semelhante foi reservado para espaços insulares como as Orkney, Shetland e Faröe, arquipélagos da borda européia alcançados, a partir da Escandinávia, pela expansão viking ${ }^{9}$, cuja natureza original foi extirpada sem maiores delongas, assim como para a Ilha Maurício e Kerguelen, ambas situadas no Índico, abordadas pelos europeus durante a expansão marítima e comercial (DIAMOND, 2005:219/258).

\footnotetext{
$7 \mathrm{O}$ início do povoamento da América tem sido reavaliado mediante a descoberta de novos jazigos arqueológicos. Se contada exclusivamente pelos registros fósseis da chamada 'paleontologia física', o Homo sapiens teria povoado 0 continente por volta de 14 mil anos atrás. Mas pela antropologia molecular, baseada no estudo do DNA de populações modernas, a data recua alguns milhares de anos. Evidências genéticas apontam para uma colonização anterior a 14 mil anos, segundo estudos apresentados no $51^{\circ}$ Congresso Brasileiro de Genética (Manchetes Socioambientais, edição de 12-09-2005).

${ }^{8}$ Acredita-se que os ocupantes de Madagascar desembarcaram na ilha apoiados em expedições canoeiras provenientes de Bornéu, na Insulíndia, no período entre 200 AC e 500 DC. Em princípio, esses povoadores humanizaram um espaço que se configurava como um dos últimos territórios virgens para a espécie humana.

9 Os vikings se substantivavam bem mais como entidade sociológica do que antropológica. Neste sentido, não constituiam propriamente uma etnia, mas sim um conjunto de povos de origem germânica assentados originalmente em diversas paragens da Escandinávia e posteriormente, em outros pontos da Europa (Normandia, Rússia, Sicilia, GrãBretanha, Irlanda. Ilha de Man) e da América Boreal (Groenlândia). 0 termo parece derivar do germânico antigo vikingar: saqueadores.
} 
Notadamente, a adoção da agricultura, ao promover o surgimento de campos de cultivo que numa definição sumária constituem nada mais nada menos do que "ecossistemas simplificados" - derivou em alterações ambientais ainda mais abruptas. Como se sabe, o chamado Fértil Crescente - o arco geográfico formado pelo Nilo, Mesopotâmia e Levante - um dos berços históricos da agricultura, foi outrora vegetado com florestas de cedro, pântanos regurgitantes de peixes, répteis e pássaros, campos pespontados com tufos de gramíneas e savanas ricas de fauna e flores, dos quais hoje, quando muito, restam escassas reminiscências.

No Egito em particular, uma ação humana bem documentada permite captar a amplitude da transformação da paisagem. O espaço egípcio no período faraônico exibia características ambientais marcadamente diferentes da natureza original. Na sua totalidade, o curso do grande rio foi verdadeiramente transformado em um imenso oásis ${ }^{10}$. Na calha do rio Nilo, a planície atual estende-se sobre o que foi milênios atrás, um terreno dominado pela naturalidade. Desapareceram densas concentrações de palmares, verdadeiras florestas de palmeiras. Além do recuo do deserto, os pântanos com sua fauna e flora foram praticamente liquidados:

\footnotetext{
"Antigamente, no limiar dos aluviões anuais, os confins do deserto eram charcos cobertos de grandes juncos ondulantes, povoados por milhares de espécies de aves e por numerosa fauna de pequenos carnívoros. O Delta não apresentava esse aspecto de vasta e monótona planície que hoje conhecemos. Devia ser bastante semelhante aos incertos pântanos que ainda hoje subsistem às portas de Alexandria" (SAUNERON, 1970:51).
}

Paralelamente, a atividade dos agricultores tradicionais, implicando na seleção empírica do germoplasma, foi origem dos modernos exemplares de plantas como o milho, arroz, feijão, gergelim, fava, tremoço, repolho, aspargo, erva-doce, batata, batata doce, mandioca, trigo, cevada, centeio, inhame, pimentas, tomate, cacau, alface, aveia, amendoim, fava, café, ervilha, agrião, milhete, sorgo, etc ${ }^{11}$, os quais, a partir de áreas do mundo notabilizadas por uma maior diversidade genética

\footnotetext{
10 Lembra o historiador Jean VERCOUTTER, um oásis "não é apenas uma mancha verde sobre uma extensão amarela, como nossos Atlas nos ensinaram a imaginá-lo". Na realidade, um oásis é constituído por um conjunto de condições físicas e humanas tão intimamente associadas que basta faltar uma para que este espaço dito "natural", deixe de existir. "Estas condições são em número de três: presença de água, terra arável e, trabalho humano [...] 0 milagre egípcio, 0 único, é que o Nilo fornece simultaneamente, a água e a terra arável, tudo o mais é devido ao homem" (1974:17).

11 Note-se que paradoxalmente, embora fruto do labor humano, essas espécies terminaram "naturalizadas" no transcorrer da história e percebidas como provenientes do meio natural ou então, assimiladas como um presente oferecido aos humanos pelas divindades.
} 
das espécies cultivadas - os chamados Centros de Vavilov ${ }^{12}$ - foram disseminados pelos mais diferentes recantos do ecúmeno (WALDMAN, 1997).

Quanto à domesticação dos animais, a pecuária amparou a proliferação ou mesmo a criação de novas espécies, concentrando seus esforços na seleção de reduzido conjunto de espécies da fauna, que dotadas então de pendores especializados, foram a seguir aclimatadas em outros espaços e privilegiadas como elementos de base pelas economias antigas. Estas seriam, de acordo com o geógrafo Roland BRETON: a cabra e o carneiro no Crescente Fértil, o asno no Egito, o boi e o pato no sul da Europa, o boi zebu e talvez a galinha e o porco na Índia, o búfalo aquático no Sudeste Asiático, o iaque no Tibet, o camelo da Tartária na Ásia Central, o dromedário nos desertos da Arábia, o cavalo nas estepes da Eurásia, a rena na Tundra, o peru na América do Norte e finalmente, a cobaia, a lhama e a alpaca na América do Sul (1990:47).

Importaria rubricar que tais inovações, em vista de se desdobrarem em desajustes genéticos, hidrológicos, climáticos, pedológicos e biogeográficos, afetaram a fisionomia e 0 funcionamento das paisagens de modo irregovável. Por sinal, as seqüelas das condutas do homem tradicional quanto ao uso dos recursos naturais chamaram a atenção de mais de um estudioso. Eis como o olhar de Friedrich ENGELS rastreou esses eventos:

\begin{abstract}
"Os homens que na Mesopotâmia, na Grécia, na Ásia Menor e noutras partes destruíram os bosques para obter terra arável, não podiam imaginar que dessa forma, estavam dando origem à atual desolação dessas terras ao despojá-las de seus bosques, isto é, dos centros de captação e acumulação de umidade. Os italianos dos Alpes, quando devastaram, na sua vertente Sul, os bosques de pinheiros, tão cuidadosamente conservados na vertente Norte, nem sequer suspeitavam que, dessa maneira, estavam arrancando, em seu território, as raízes da economia das granjas leiteiras; e menos ainda suspeitavam que assim estavam eliminando a água das vertentes da montanha, durante a maior parte do ano e que, na época das chuvas, seriam derramadas furiosas torrentes sobre as planícies" $(1979: 224)$.
\end{abstract}

Porém, se podemos arrolar procedimentos que questionam a imagem romântica de "sociedades ecológicas" organizadas na pré-Modernidade, de outra parte, é necessária certa cautela na aferição

\footnotetext{
12 Os Centros de origem de Vavilov - referência ao notável biólogo soviético Nicolai Ivanovich Vavilov (1887-1943) consistem de oito grandes territórios separados geograficamente por desertos, planícies, rugosidades montanhosas e grandes massas oceânicas, alguns dos quais subdivididos, nos quais se processou grande parte da domesticação de espécies.
} 
da performance ambiental das formações sociais do passado e mais ainda, quanto às falsas analogias que imprudentemente são tecidas comparando o mundo tradicional com o moderno.

Conforme destacado, o mundo tradicional foi estruturado com base em premissas discrepantes das que comandam a Modernidade. Tomando apenas esse ângulo como vertente de avaliação, nada permite conectar os desequilíbrios ambientais no passado com os que surgem com 0 advento da sociedade contemporânea. Na prática, a crise ambiental na Antiguidade, mesmo nos seus piores cenários, irrompia em sinergia com determinações dessemelhantes das que conhecemos e nesse exato sentido, possuía origens e impactos diferentes dos que caracterizam a crise ambiental da Modernidade (WALDMAN, 2008, 2006a, 2006b e 1997).

Por isso mesmo, note-se em primeiro lugar que em contraste com o mundo moderno, as sociedades sob comando da Tradição não estavam obcecadas pela preocupação de aumento constante de bens materiais, nem em ofertar maior conteúdo tecnológico às formas estabelecidas de produção. A sociedade tradicional, inversamente ao mundo moderno, advogava uma firme determinação pelo não-desenvolvimento das forças produtivas, explicitando, através de sucessivos modos de relação com a natureza, um diálogo permanente da artificialidade com a naturalidade.

Uma segunda consideração, é que as sociedades tradicionais foram gravadas por uma naturalidade da metamorfose - isto é, uma artificialidade empapada pelos fluídos da natureza evidência válida desde a mais "rústica" sociedade de caçadores-coletores até os grandes impérios territoriais de outrora. Mesmo na hipótese de construirmos uma proposição dispondo, numa ordem ascensional, uma sequência de formações sociais acatando um gradativo distanciamento do meio natural, ainda assim nos depararíamos com versões de territorialidades nas quais o espaço, em maior ou menor grau, continuaria mesclado com as pulsões do meio natural. Estruturalmente - num sentido contrário ao mundo inaugurado pela Modernidade - as sociedades tradicionais, em função dos conteúdos de naturalidade organicamente entrelaçados à artificialidade, recidivamente convocaram a natureza enquanto parceira na sustentação do espaço articulado e da ordenação do tempo social. 0 mundo da Tradição, mantendo diálogo permanente com as forças naturais, apenas em situações excepcionais entabulou crispações acirradas com os dinamismos dos ecossistemas com os quais interagia.

Um terceiro ponto nodal atesta que grande parte das crises ambientais da Antiguidade não implicou na esterilização dos fluxos naturais. Hecatombes ecológicas tais como a que acometeu 
a Civilização da llha da Páscoa ${ }^{13}$, foram incomuns, distantes de constituir uma norma ${ }^{14}$. Via de regra, uma re-naturalização da paisagem humanizada desenvolvia-se pari passu com processos de reconstituição dos arranjos espaciais e/ou com a aparição de novos. Exemplificando, no que mais tarde seria definido como Europa Ocidental, o desmantelamento do escravismo romano foi sucedido por intensa revitalização do ambiente. Em muitas regiões, reapareceram matas de carvalhos e bétulas, ao passo que campos e charnecas recuperaram seus antigos limites e foram repovoados por javalis, lobos e variada fauna de aves e roedores. Freqüentemente, as "contra-ofensivas" da natureza, retomando espaços que uma vez lhe haviam sido roubados pela propensão humana em esculturar o meio natural, demonstram as limitações desse empenho e igualmente, sua relação siamesa com os ciclos ambientais mais proeminentes com os quais o homem do passado interagia. Numa notação que poderia ser multiplicada para diversificado rol de contextos, a renaturalização dos espaços humanizados borrava inclusive o reconhecimento de finadas orquestrações civilizatórias ${ }^{15}$.

Sintetizando, conquanto as crises ambientais do mundo antigo possam ter assumido cores drásticas e pungentes, não haveria como igualá-las com a crise ambiental da Modernidade. Nos dias de hoje, estão ausentes aqueles epifenômenos que justamente personalizavam a débâcle das sociedades pré-modernas. No passado, o mundo tradicional configurava um Cosmos-Natureza, pontilhado aqui e ali por espaços mais estruturados ou caracterizados por uma maior agregação de artificialidade. Contudo, estavam sujeitos a serem resgatados a qualquer instante por aquelas porções ainda menos buriladas pelos humanos. Comumente, a articulação ambiental da sociedade nutria-se da heterogeneidade, da compartimentação e das pulsões presentes no meio ambiente, fatoração tributária da sólida aliança mantida pelos enunciados da concretude social e da vida espiritual com os fluxos naturais. Essa evidência, despontando continuamente em todo o mundo prémoderno, encontrou expressão numa coletânea de simbolismos presentes nas lides do cotidiano, na

\footnotetext{
13 Há quem conteste o uso do conceito de civilização para a llha da Páscoa. Sentenciamento incontestável, uma das mais fortes evidências de uma civilização é a existência de vida urbana, fato rigorosamente ausente em Páscoa.

14 Em Páscoa, um território irrisório $\left(163 \mathrm{~km}^{2}\right)$, isolado no Pacífico Oriental e distante cerca de 3.700 quilômetros do litoral sul-americano, quase todos os recursos ecológicos locais foram esgotados, induzindo um severo colapso dos equilíbrios ambientais, cuja derrocada, tragou violentamente o status quo (DIAMOND, 2005:105-152).

15 "Desse modo, certas regiões, atualmente abandonadas pelos homens e que aparentam jamais terem sido povoadas, são na realidade setores transformados e empobrecidos por uma ação humana inconscientemente devastadora. A floresta que se estende ao Sul do Yucatán, na proximidade da fronteira guatemalteca, é quase desabitada. Ora, essa mesma região foi um dos focos da civilização maia, há uma dezena de séculos atrás" (DOLLFUS, 1972:32).
} 
arte e na religião, dos quais os objetos espaciais ${ }^{16}$ - obras que atam a energização social do tempo e do espaço - ao interagirem com a espessura úmida da natureza, se tornaram seus epítomes inquestionáveis (passim WALDMAN, 2006a e 1997).

Neste sentido, a discussão da crise ambiental nos termos colocados pela sociedade contemporânea, pouco ou nada compartilha problemáticas com os primados consentidos pelos humanos da pré-Modernidade. Notadamente, o fortalecimento da sociedade contemporânea contou com um horizonte temporal de novo tipo, empoderado da autoridade de parâmetro dominante nas expectativas imaginárias e concretas do sistema. Essa nova interpretação do tempo social - definida como linear e progressiva - afirma-se na apologia da rapidez, da velocidade, da transitoriedade e na prevalescência da fruição linear da temporalidade ${ }^{17}$.

Assim, ao contrário das culturas tradicionais, nas quais o passado era honrado e seus símbolos valorizados por conterem a experiência de gerações, na Modernidade o tempo pretérito foi esvaziado de sentido. 0 mundo contemporâneo é regido por um universo de valores no qual 0 presente tornou-se um instante fugidio, um lapso que se apaga automaticamente na transcorrer do passado para o futuro. A passagem do tempo, ao metamorfosear tudo em passado, torna-se volátil e contrafatual. Deste modo, a temporalidade deixa de vincular-se com a segurança ontológica das pessoas. Com a derrocada da fruição tradicional do tempo - mormente das suas leituras cíclicas e naturais - os humanos se desligaram de uma intelecção orgânica da temporalidade e subseqüentemente, dos ritmos da natureza (GOUREVITCH, 1975:282/283).

Fato óbvio, mas que sempre reclama reapresentação, as proposições do tempo, uma vez configurando um fenômeno social, não podem ser dissociadas das propensões objetivas da sociedade ocidental. Nesse prisma, uma das pontuação de destaque na identificação do móvel central da Modernidade é a que transita na obra A Grande Transformação: As origens da nossa época, texto do filósofo e historiador húngaro Karl Polanyi (1886-1964). Publicado em 1944, esse livro, considerado uma das contribuições intelectuais mais expressivas do século XX, nem de longe aparenta somar seis décadas de circulação. Na sua exposição, Polanyi discute como a instituição

\footnotetext{
${ }^{16}$ No pensamento do geógrafo Milton SANTOS, os objetos espaciais configuram acréscimos que ofertam ao espaço conteúdos técnicos e funcionais, imbuídos da artificialidade condizente aos sistemas que os engendraram e animados por sistemas de ações tendentes è legitimá-los enquanto peças a soldo de determinado sistema de engenharia (1999:51).

${ }^{17}$ Aparte situações nas quais as terminologias tempo e temporalidade convivem em condição de sinonímia, em outras, nos remetem a dois conceitos diferentes: enquanto que tempo implica em um entendimento de uma acepção social mais geral, temporalidade diria respeito à forma como diferentes apreensões da fruição do tempo se desenvolve no interior do espaço de uma determinada sociedade.
} 
novicentista do liberalismo econômico - por ele equiparado ao mercado auto-regulador - teve sua supremacia alavancada por intermédio da destruição da antiga coesão social, subjugada por um sistema no qual coube à esfera do econômico, o comando exclusivo da sociedade.

Este feito, sublinhado como único na história humana, hodiernamente configura posição ratificada por amplo espectro de cientistas sociais. Nas palavras de Karl POLANYI, essa nuança é desvelada como segue:

\footnotetext{
"Todos os tipos de sociedades são limitados por fatores econômicos. Mas, somente a civilização do século XIX foi econômica em um sentido diferente e distinto, pois ela escolheu basear-se num motivo muito raramente reconhecido como válido na história das sociedades humanas e, certamente, nunca antes elevado ao nível de uma justificativa de ação e comportamento na vida cotidiana, a saber, o lucro. 0 sistema de mercado autoregulável derivou exatamente desse princípio" (2000:47).
}

Neste sentido, a organização do tempo no capitalismo advoga uma materialidade cadenciada pelos ritmos incessantes do tempo da produção, da circulação, do consumo e da realização da mais valia (passim SANTOS, 1988). A dimensão cósmica que sempre havia habitado o tempo e o espaço, entrelaçando ambos e os unindo simultaneamente aos humanos, foi abolida e substituída por uma outra, de cunho eminentemente prático e quantitativo, descolando o tempo do espaço. A ruptura da parceria com o espaço representou a possibilidade do tempo substantivar-se em uma cronologia temporal alheia a qualquer outra determinação, e por essa via, dotada de um certo sentido de velocidade que é a marca por excelência da Modernidade.

No que há de singular, nada semelhante à temporalidade moderna pode ser localizado no passado do homem. A temporalidade inaugurada pela economia de mercado é alheia aos ciclos presentes no espaço natural, que outrora foram referência determinante para a organização do próprio tempo social. Uma vez extintos os laços de solidariedade que sempre haviam conectado de forma inquebrantável o espaço ao tempo, sobreveio, pois uma hegemonia inconteste do tempo. $\mathrm{Na}$ Modernidade - e apenas com ela - é que o espaço passa a ser verdadeiramente o resultado de uma produção, emanação direta do tempo, seu resultado objetivo, concreto e material.

Em face do exposto, caberia destacar a impropriedade de discutir a crise ambiental desvinculada de balizas históricas e geográficas, desprovida dos suportes culturais e sociais, estacas que justamente asseguram à esfera do econômico, a proeminência que alcançou no seio da Modernidade. Veredicto inevitável, a explosiva equação que molda a crise ambiental dos nossos dias torna-se única até porque, expressa contradições que tipificam exclusivamente o modo de vida 
moderno. Consecutivamente, esse pano-de-fundo permite a apresentação de um elenco sumário de aspectos que denunciam a personalidade da crise ambiental contemporânea e os desdobramentos pertinentes à sua lógica. Estes, a saber, seriam:

Primeiramente, a crise nos dias atuais diferencia-se das que eclodiram no mundo tradicional pelo seu caráter inexorável. No passado, ao menos em princípio, a perdurabilidade e a estabilidade do arranjo territorial é que se colocava como a hipótese mais provável para uma sociedade na sua projeção histórica e geográfica ${ }^{18}$. Todavia, o desencaixe do tempo com o espaço proposto pela civilização ocidental não admite tal prognóstico. 0 cadenciamento do tempo no mundo contemporâneo sustenta uma contradição irrefreável para com o meio natural, cujo pressuposto básico, o predomínio das dinâmicas temporais sobre as espaciais, faz com que a propensão do sistema se volte inclusive contra a arquitetura da artificialidade que ele mesmo esboçou. No mundo moderno, a reconstrução permanente do espaço, sua transitoriedade e sua contínua remodelagem, expressa um dinamismo autofágico do sistema, retratado num desequilíbrio ambiental estrutural (WALDMAN, 2006a, 2006b, 1994b).

Em segundo lugar, a partir do momento em que a crise da Modernidade se especifica em função de um caráter eminentemente temporal, seria factível pontuar que o mundo moderno tende a responder frente à sua crise do meio ambiente, lançando mão da introjeção de conteúdos ainda maiores de tempo ao espaço a não como outrora, pela incorporação de mais espaço ao tempo. Essa estratégia temporal se especifica, por exemplo, nas inovações tecnológicas high tech, primando por padrões presenciais e rapidez cada vez mais exacerbados. Daí que as fibras óticas, os sistemas on line, a telefonia celular, os satélites, a robótica, a informática, a mecatrônica e as redes computadorizadas, dentre outros dispositivos, aparatos e gadgets, tornaram-se ícones do sistema de engenharia da Modernidade, epifenômenos que de modo não aparente para a imensa maioria dos humanos, constituem expressão imanente de sua própria entropia (WALDMAN, 1997).

Um terceiro ponto, e uma vez mais diferentemente do passado, dado que o padrão temporal dominante tem seu cerne na ruptura radical para com o tempo-espaço da natureza, a exaustão do padrão civilizatório existente - that is to say: seu colapso ambiental - não tem como suscitar uma revitalização posterior do espaço habitado. Na artificialidade rígida que irrompe das

\footnotetext{
${ }^{18}$ Nessa visada, recorde-se que sociedades como a dos Inuit no Ártico, dos Nuer do Sudão, dos Yanomami sul-americanos, dos Saami da Escandinávia e dos Papuas da Nova Guiné, lograram reproduzir durante séculos ou mesmo por vários milênios, estratégias ecologicamente perduráveis de utilização dos recursos naturais.
} 
entranhas do tempo linear e progressivo, estão colocados handicaps que contradizem a orgulhosa auto-imagem da Modernidade. $O$ que temos pela frente é um admirável mundo novo cheio de brumas, de chuva ácida intermitente, de plásticos, de corrosivos, de penumbra, de vazio, de solidão e de altos edifícios. Não admira, pois a suspeita intuitiva que assombra a consciência moderna quanto à falibilidade da Gessellschaft. Esse sentimento impulsiona, por exemplo, uma profícua produção cinematográfica versando sobre os inglórios tempos posteriores ao desastre final, antecipação apologética dos limites da Modernidade e do quão pouco que poderá ser feito para corrigir esses rumos (WALDMAN, 2011a, 2008 e 1994b).

Um quarto apontamento, decorrente do esmiuçamento do argumento anterior, é que a ordenação dos arrazoados da crise ambiental contemporânea, ao se revestirem de determinações não restritas a um padrão clássico e ao mesmo tempo, incluírem novas - como o desencaixe do tempo com o espaço - sinalizam simultaneamente para duas direções. Uma delas está materializada nas "respostas" emitidas pelo meio natural como resultado das agressões provenientes da natureza socializada, inscrevendo-se na clássica formulação engelsiana das vinganças da natureza (ENGELS, 1979:223). Outra derivação significativa - e nisso o mundo moderno difere fundamentalmente da Antigüidade - presenciamos desequilibrios que resultantes da artificialização do mundo, se traduzem pela artificialidade dos elementos que compõem a sua crise. Na vida social moderna, os distúrbios "ecológicos" são eminentemente laicos. Contrariamente ao mundo da Tradição, em vista dos transtornos derivarem exclusivamente do saber institucionalizado, os riscos ambientais tornaram-se virtualmente secularizados. Não há mais lugar para propiciações mágicas ou explicações de índole cosmológica. Na realidade, o homem moderno defronta-se, na crise ambiental, com a crise do seu próprio devir enquanto proposta civilizatória (passim WALDMAN, 1992a, 1992b e 1992c).

Isso posto, a Modernidade, ao ter se posicionado em defesa intransigente do indivíduo, do triunfo sobre o meio natural e de uma mundialização cujos paradigmas são aqueles que ela própria criou para seu deleite narcisista, encontra-se numa encruzilhada crucial, ou como frisamos recentemente em outro texto, diante de um dilema (WALDMAN, 2011a). Factualmente, ao contrário das antigas sociedades tradicionais, o mundo moderno não dispõe das estruturas cognitivas pelas quais as sociedades de outrora se afirmavam através de um diálogo sensível com a natureza, com o universo e o Cosmos. Vítima de sua própria racionalização do mundo e da "despaganização" do mundo, o ocidente defronta-se, angustiado, com os perigos laicos gerados pela dessacralização de 
valores, crenças e posturas que durante a maior parte da história da Humanidade, constituíram o suporte sensível da percepção da realidade. Somos diariamente bombardeados por problemas que, por sua intratabilidade, passam para um segundo plano numa busca premeditada de desatenção civil.

Certo é que as desventuras desta empreitada não passaram despercebidas a muitos pensadores do próprio mundo ocidental. Dentre outras advertências, devemos a Sigmund Freud a célebre sentença mal-estar da cultura, título de conhecido ensaio homônimo, no qual o fundador da psicologia, alarmado com as implicações do padrão civilizatório em vigor, advertia sobre as possibilidades de destruição total conferidas pelo processo de racionalidade embasado na técnica e na ciência em favor da violência voltada contra os próprios humanos. Eis como o pai da psicanálise simultaneamente concluía e delineava as conseqüências da propensão da razão ocidental em negar, ignorar ou desqualificar os tentames sensiveis que imemorialmente haviam garantido segurança aos humanos:

\footnotetext{
"Os homens alcançaram um domínio tal sobre as forças da natureza que se lhes tornou difícil hoje em dia servir-se delas para se exterminarem até o último. Eles sabem disto, e daí provém uma boa parte da inquietação atual, de seu mal-estar e de sua angústia. É de se esperar que o outro dos dois poderes celestes, o Eros eterno faça um esforço em afirmar-se na luta contra seu adversário, o Thanatos, também eterno. Mas quem é que poderá prever o resultado e o desfecho?" (in LEÃO, 1992:225).
}

Esta severa admoestação de Freud não pode, em hipótese alguma, ser deixada de lado. Ignorá-la apenas fortalece um sentimento capitulacionista que aparentemente se aninhou em muitos interstícios da consciência do homem contemporâneo. Trata-se de uma visão pessimista pela qual nada mais poderia ser feito, no qual sub-repticiamente os problemas que nos acodem, considerados insolúveis e intratáveis, ao invés de despertar a consciência, amortecem a visão crítica e a tomada de posição.

Contudo, não há como evitar o questionamento de valores e concepções que regem a vida contemporânea. Em particular, o que se exige é um convite para um repensar especial da relação com a natureza. Definitivamente, pelo fato da Humanidade estar submetida a uma dinâmica impessoal, acelerada e artificial, muitos parecem ter se esquecido que na história, ao lado da evolução, a estabilidade desempenhou papel fundamental (GOUREVITCH, 1975:282/283). 
Que seja então colocado o debate dos rumos do mundo moderno, seus projetos, anseios e expectativas.

\section{REFERÊNCIAS BIBLIOGRÁFICAS}

\section{LIVROS}

1. ALIER, Juan Martinez. El Ecologismo de Los Pobres - Conflictos Ambientales y Lenguajes de Valoración. Icaria-Antrazyt-Flacso, 2006, Barcelona, Espanha. 2005;

2. BALANDIER, Georges. As Dinâmicas Sociais: sentido e poder. São Paulo (SP): DIFEL Difusão Européia do Livro. 1976;

3. BRETON, Roland J. L. Geografia das Civilizações. Série Fundamentos, $n^{0} 60$. São Paulo (SP): Editora Ática. 1990;

4. CROSBY, Alfred W. Imperialismo Ecológico: a expansão biológica da Europa: 900-1900. $1^{\text {a }}$ reimp. São Paulo: Companhia das Letras, 2000;

5. DIAMOND, Jared. Colapso: como as sociedades escolhem o fracasso ou o sucesso. São Paulo: Record, 2005;

6. DOLLFUS, Olivier. O Espaço Geográfico (Col. Saber Atual, 153). São Paulo (SP): DIFEL Difusão Européia do Livro. 1972;

7. ELLIOTT, Lorraine. The Global Politics of the Environment. Reino Unido: Macmillan, 1998;

8. ENGELS, Friedrich. A Dialética da Natureza. (Col. Pensamento Crítico, 8). Rio de Janeiro (RJ): Paz e Terra, 1979;

9. LÉVI-STRAUSS, Claude. Raça e História. In: Perspectiva, 1970; - Raça e Ciência. São Paulo:

10. POLANYI, Karl. A Grande Transformação: as origens da nossa época. $8^{a}$ ed. Rio de Janeiro: Campus, 2000;

11. RIZZINI, Carlos Toledo. Tratado de Fitogeografia do Brasil: Aspectos Ecológicos. São Paulo: HUCITEC; EDUSP, 1976;

12. SANTOS, Milton. A Natureza do Espaço - técnica e tempo, razão e emoção. $3^{a}$ edição. São Paulo: Hucitec. 1999;

13. Metamorfoses do Espaço Habitado: fundamentos teóricos e metodológicos da geografia. Texto escrito com a colaboração de Denise Elias. São Paulo: Hucitec, 1988;

14. Por Uma Geografia Nova. São Paulo: EDUSP; Hucitec, 1978. 
15. SAUNERON, Serge. A Egiptologia, Coleção Saber Atual. São Paulo (SP): DIFEL - Difusão Européia do Livro. 1970;

16. VERCOUTTER, Jean, O Egito Antigo. Coleção Saber Atual, nº 164. São Paulo (SP): DIFEL Difusão Européia do Livro. 1974;

17. TOFLER, Alvin. O Choque do Futuro. 1a edição. São Cristóvão (RJ): Editora Arte Nova. 1973;

18. TOYNBEE, Arnold. A Humanidade e a Mãe-Terra - Uma História Narrativa do Mundo, 2a edição. Rio de Janeiro (RJ): Zahar Editores. 1979:

19. TUAN, Yi Fu. Topofilia: um estudo da percepção, atitudes e valores do meio ambiente. São Paulo: DIFEL, 1980.

20. WALDMAN, Maurício. Lixo: Cenários e Desafios - Abordagens básicas para entender os resíduos sólidos. São Paulo (SP): Cortez Editora, 2010;

21. Meio Ambiente \& Antropologia. 1 $^{\text {a }}$ ed. São Paulo (SP): Editora SENAC. 2006a;

22. Ecologia e Lutas Sociais no Brasil. $8^{a}$ ed. São Paulo: Contexto (Col. Caminhos da Geografia). 1992a;

23. WALDMAN, Maurício et SERRA, C. Memória D'África - A Temática Africana em Sala de Aula. São Paulo: Cortez Editora. Saiba mais: http://www.mw.pro.br/mw/mw.php?p=antrop_memoria_d_africa\&c=a. 2007.

\section{TESES}

1. WALDMAN, Maurício. Água e Metrópole: Limites e Expectativas do Tempo, Tese de Doutorado em Geografia. Departamento de Geografia da FFLCH/USP, São Paulo, SP. Disponível em: $<$ http://www.teses.usp.br/teses/disponiveis/8/8136/tde-20062007-152538/>. Acesso em: 12-112009. 2006a;

\section{TEXTOS CLÁSSICOS}

1. Commentarii de Bello Gallico - The Gallic Wars, by Julius Caesar (menu page linking 8 books). Translated by A. McDevitte and W.S. Bohn (1869), Classics.MIT.edu. Acesso: http://classics.mit.edu/Caesar/gallic.html. 2009

\section{ARTIGOS E PAPERS}

1. ALIER, Juan Martinez. El Ecologismo de Los Pobres. Envio, $n^{0} 125$, Publicação mensal da Universidade Centro Americana de Manágua. Nicarágua: Manágua. 1992; 
2. COUTINHO, Leopoldo Magno. Queimadas e Floração. O Estado de São Paulo, São Paulo, Suplemento Cultural, $n^{0} 13$, ano I, p. 4-5, 1977;

3. GOUREVITCH, A.Y. O Tempo como problema de História Cultural. In: UNESCO. As Culturas e o Tempo. Petrópolis: Vozes; São Paulo: EDUSP. 1975;

4. HARRIS, David H. A Ecologia Humana em Meio Ambiente de Savana. Revista Brasileira de Geografia, Rio de Janeiro, Fundação IBGE, ano 44, nº 1, jan./ fev. 1982;

5. LEÃO, Emmanuel Carneiro. Modernidade e Violência, in Democracia e Diversidade Humana: Desafio Contemporâneo, Juana Elbein dos Santos (org.), Salvador, Bahia. 1992;

6. PASCHOAL, Adilson D. Agricultura e Conservação dos Recursos Naturais. Jornal O Estado de S. Paulo, São Paulo, Suplemento Cultural, nº 75, p. 7-8, 26 mar. 1978;

7. RECUERO, Raquel da Cunha. Comunidades Virtuais: Uma Abordagem Teórica. V Seminário Internacional de Comunicação. PUC-RS, GT de Comunicação e Tecnologia das Mídias. 2001;

8. TAKS, Javier; FOLADORI, Guillermo. La Antropología Frente al Desafío Ambiental. Mad, publicação eletrônica semestral de Antropologia da Faculdade de Ciências Sociais da Universidade do Chile, 2002;

9. WALDMAN, Maurício. Limites da Modernidade: Dilemas do Esgotamento dos Recursos. Paper XII Simpósio de Iniciação Científica da Faculdade de Ciências, Letras e Educação de Presidente Prudente. Universidade do Oeste Paulista, Presidente Prudente (SP): FACLEPP. 2011a;

10.

O Baobá na Paisagem Africana: Singularidades de uma Conjugação entre Natural e Artificial. Texto de subsídio elaborado para o XIII Curso de Difusão Cultural do CEA-USP. São Paulo (SP): Centro de Estudos Africanos da USP. 2011b;

11. Arquétipos, Fantasmas e Espelhos, in Revista Geousp n² 23, Publicação de PósGraduação do Depto de Geografia da FFLCH-USP, São Paulo (SP). Geousp, v. 1, p. 44-63, 2008;

12. Imaginário, Espaço e Discriminação Racial. Geousp, São Paulo, n 14, Espaço e Tempo, p. 45-64. (Publicação da Pós-Graduação do Depto de Geografia da FFLCH-USP). 2004;

13. Hegemonia Européia: Processo Histórico e Social, in Curso de Geografia para o Ensino Fundamental. São Paulo (SP): Editora Didática Suplegraf. 1999;

14. Metamorfoses do Espaço Imaginário: Um ensaio "topo-lógico" relativo ao universo da cultura, do espaço e do imaginário. 1997. Dissertação (Mestrado em 
Antropologia Social) Departamento de Antropologia, Universidade de São Paulo. São Paulo. 1997;

15. Espaço e Modo de Produção Asiático. AGB - Associação dos Geógrafos Brasileiros, seção local São Paulo: Boletim Paulista de Geografia, São Paulo, n 72, pp. 29/62. 1994a;

16.

Tempo, Modernidade e Natureza. Caderno Prudentino de Geografia, Presidente Prudente, $n^{0} 16$, pp. 24-73, set. 1994. Disponível em: <http://www.mw.pro.br>. Acesso em: 25 jun 2004. (AGB - Associação dos Geógrafos Brasileiros, Seção de Presidente Prudente). 1994b;

17. Divisão Internacional dos Riscos Técnicos e Ambientais. Tempo e Presença (Publicação do CEDI), São Paulo e Rio de Janeiro, n 261, Edição Especial Meio Ambiente, jan.-fev. 1992b.

\section{DEPOIMENTOS}

1. WALDMAN, Maurício. Machtlose Umweltpolitik. Depoimento prestado para a revista Latein Amerika Nachriten. República Federal da Alemanha: Berlim, $n^{\circ}$ 221, páginas 22-44. Novembro 1992c.

\section{INFORMATIVOS ELETRÔNICOS}

1. Manchetes Socioambientais, informativo eletrônico elaborado pelo Instituto Socioambiental, São Paulo (ISA), São Paulo.

Artigo recebido em: 02/10/2011

Aprovado em 01/11/2011 